\title{
Prone Positioning Improves Ventilation-Perfusion Matching Assessed by Electrical Impedance Tomography in Patients with ARDS: A Prospective Physiological Study
}

\author{
Yu-xian Wang \\ Zhongshan Hospital of Fudan University \\ Ming Zhong ( $\sim$ zhong.ming@zs-hospital.sh.cn ) \\ Zhongshan Hospital of Fudan University \\ Min-hui Dong \\ Zhongshan Hospital of Fudan University \\ Jie-qiong Song \\ Zhongshan Hospital of Fudan University \\ Yi-jun Zheng \\ Zhongshan Hospital of Fudan University \\ Wei Wu \\ Zhongshan Hospital of Fudan University \\ Jia-le Tao \\ Zhongshan Hospital of Fudan University \\ Ling Zhu \\ Zhongshan Hospital of Fudan University \\ Xin Zheng \\ Zhongshan Hospital of Fudan University
}

\section{Research Article}

Keywords: electrical impedance tomography, prone positioning, acute respiratory distress syndrome, ventilation-perfusion matching, mechanical ventilation, pulmonary perfusion

Posted Date: February 28th, 2022

DOl: https://doi.org/10.21203/rs.3.rs-1388270/v1

License: (c) (i) This work is licensed under a Creative Commons Attribution 4.0 International License. Read Full License 


\section{Abstract}

Background: The physiological effects of prone ventilation in ARDS patients have been discussed for long but remained not fully elucidated. Electrical impedance tomography (EIT) emerged as a tool for bedside monitoring of pulmonary ventilation and perfusion, giving the chance to find proofs. This study aimed to investigate the effect of prone positioning (PP) on ventilationperfusion matching by contrast-enhanced EIT in patients with ARDS.

Design: Monocenter prospective physiologic study.

Setting: University medical ICU.

Patients: Ten mechanically ventilated ARDS patients who underwent prone positioning.

Interventions: We performed EIT evaluation at the initiation of PP, 3h after PP initiation and at the end of PP during the first PP session.

Measurements and Main Results: The regional distribution of ventilation and perfusion was analysed based on EIT images and compared to the clinical variables regarding respiratory and hemodynamic status. Prolonged prone ventilation improved oxygenation in the ARDS patients. Based on EIT measurments, the distribution of ventilation was homogenized and dorsal lung ventilation was significantly improved by PP administration, while the effect of PP on lung perfusion was relatively mild, with increased dorsal lung perfusion was observed. After merging, the ventilation-perfusion matched region was found to increase and correlate with the increased $\mathrm{PaO}_{2} / \mathrm{FiO}_{2}$ by $\mathrm{PP}$, which was mainly attributed to reduced shunt in the lung based on further quantification showed decrease of the only perfused regions.

Conclusions: Prolonged prone ventilation increased dorsal ventilation and perfusion, which resulted in improved ventilationperfusion matching and oxygenation.

Trial registration: ClinicalTrials.gov, NCT04725227. Registered on 25 January 2021.

\section{Introduction}

Prone positioning (PP) has been used for long in ARDS patients who received mechanical ventilation for oxygenation improvement and lung protection purposes [1, 2], and has been shown associated with improved survival in selected ARDS patients [3]. Physiologically, PP reduces ventilator-induced lung injury (VILI) by improving lung homogeneity, promoting alveolar recruitment and reducing hyperinflation [4]. For oxygenation improvement, PP restores lung aeration, decrease shunt while preserve perfusion in dorsal lung regions without impairing gas exchange in ventral regions, which consequently improve ventilation-perfusion matching in the injured lung [5-8]. However, although these physiological findings have been widely acknowledged, most of them were derived from animal models and direct evidence was hardly ever observed in patients due to the lack of proper harmless evaluation methods over the past decades.

The emergence of electrical impedance tomography (EIT) has been promisingly removing the bottleneck. As a radiation-free and non-invasive technique, EIT, which images regional impedance distribution in a cross-sectional area of the body, provides realtime visualization of lung ventilation at the bedside [9], besides, contrast-enhanced EIT allows concurrent estimation of regional pulmonary perfusion based on the kinetics of a bolus of hypertonic saline contrast injected through a central venous line [10, 11]. With these characteristics, EIT is no doubt an ideal tool for dynamic evaluation of pulmonary physiological changes, especially for regional ventilation-perfusion matching in ARDS patients, which remains poorly illustrated. Recently, studies involving EIT for lung ventilation assessment have revealed notable effects of PP on ventilatory mechinics in ARDS patients, including regional gas redistribution, improved alveolar recruitment and lung homogeneity[7, 8, 12, 13]. Even though, few study has set to demonstrate the influence on pulmonary ventilation-perfusion matching during PP in ARDS patients.

In this study, we aimed to evaluate the impact of PP on ventilation and pulmonary perfusion in patients with moderate to severe ARDS using contrast-enhanced EIT, trying to unveil the underlying physiological alterations beyond the improved oxygenation to 
some extent.

\section{Materials And Methods}

\section{Patients}

This prospective study was conducted in the intensive care unit (ICU) of Zhongshan Hospital, Fudan University, and was approved by the Institutional Ethics Committee of the hospital(NO.B2019-230R). All patients were recruited upon obtaining written informed consent. Inclusion criteria included moderate to severe ARDS patient (defined as $\mathrm{PaO}_{2} / \mathrm{FiO}_{2}<150 \mathrm{mmHg}$ with positive end-expiratory pressure (PEEP) $\geq 5 \mathrm{cmH}_{2} \mathrm{O}$, and $\mathrm{FiO}_{2} \geq 0.6$ according to the Berlin definition [14]) who underwent mechanical ventilation and prone positioning upon clinical decision within the first PP session. Exclusion criteria included age < 18 years, severe hemodynamic instability, pregnancy, length of prone positioning < 12 hours; contraindications to EIT administration, inability of EIT belt placement. This study was registered clinicaltrials.gov (NCT04725227).

\section{Study Protocol}

Baseline characteristics of the patients were collected at enrollment, including height and weight, acute physiology and chronic health evaluation II (APACHE II) score at ICU admission, etiology of ARDS, and arterial partial oxygen pressure to fractional concentration of inspired oxygen $\left(\mathrm{PaO}_{2} / \mathrm{FiO}_{2}\right)$ ratio.

EIT assessment was respectively administered at PP initiation $\left(T_{0}\right), 3$ hours after PP initiation $\left(T_{1}\right)$ and the end of PP $\left(T_{2}\right)$ within the first PP session. Arterial blood gas (ABG) analysis results, end-tidal expiratory carbon dioxide pressure, ventilator parameters and hemodynamic parameters including heart rate (HR), central venous pressure (CVP) and mean arterial pressure (MAP) were also recorded at $T_{0}, T_{1}$ and $T_{2}$, respectively. Ventilator settings except $\mathrm{FiO}_{2}$ remained unchanged during the PP period.

\section{EIT data}

The EIT belt containing 16 electrodes was placed around the chest wall at the forth or fifth intercostal space and connected to the EIT monitor (PulmoVista 500; Dräger Medical GmbH, Lübeck, Germany).Technical details of EIT have been previously described[11]. The EIT signals were recorded at frame rate of $50 \mathrm{~Hz}$. After a baseline recording of EIT data for $5 \mathrm{~min}$, we performed an end-inspiratory breath hold lasting $20 \mathrm{~s}$. After $2 \mathrm{~s}$ from start of the occlusion, a bolus of $10 \mathrm{ml}$ of $5 \% \mathrm{NaCl}$ solution was manually injected via the central venous catheter. The bolus of saline solution, injected in less than $2 \mathrm{~s}$, passes through the pulmonary circulation producing an impedance dilution curve that follows typical first-pass kinetics[15]. EIT ventilation mapswere obtained from offline analysis of tracings by averaging values over five consecutive respiratory cycles(Fig. S1A). From the analysis of ventilation maps we measured:[16]

1. the pixel-level ventilation measured as impedance change between expiration and inspiration. Pixels were then classified as non-ventilated if pixel ventilation was $\leq 10 \%$ of the highest pixel-level value measured in that patient

2. Tidal image region-global $(\%)=$ The relative pixel-level ventilation / the relative pixel-level detected lung size [17]

3. the percentage of ventilated pixels in the respective region (Region of Interest: ROI 1, ROI 2, ROI 3and ROI 4) (Fig. S1D)

4. Ventral/ Dorsal of tidal image region(\%) = Tidal image region-global $\times$ the ventral/ dorsal fraction of ventilation distribution

5. The Global Inhomogeneity (GI) index [18]

EIT perfusion maps (Fig. 1B) were derived from offline analysis of the time-impedance curve obtained during the first pass of the saline solution during occlusion, after removing the cardiac region from the images. From the analysis of perfusion maps we measured[16]:

1. the relative pixel-level perfusion: after preprocessing, the steepest (maximal) slope of the temporal EIT signal deflection during the saline bolus injection in each pixel was normalized to the overall detected signal, yielding the relative pixel perfusion. Pixels were classified as non-perfused if pixel perfusion was $\leq 10 \%$ of the highest pixel-level value measured in that patient 
2. Blood flow region-global $(\%)=$ The relative pixel-level perfusion $/$ the relative pixel-level detected lung size

3. the percentage of perfusion in each region (ROI 1, ROI 2, ROI 3and ROI 4) (Fig. S1D)

4. Ventral/ Dorsal of blood flow region $(\%)=$ Blood flow region-global $(\%) \times$ the ventral/ dorsal fraction of perfusion distribution

5. The Global Inhomogeneity (GI) index [18]

By integrating the pixel-level data on ventilation and perfusion (Fig. S1C), we calculated:

1. Dead Space-EIT \%: corresponding to the ventilated but non-perfused pixels divided by the total number of pixels ventilated and/or perfused

2. Shunt-EIT \%: corresponding to the perfused but non-ventilated pixels divided by the total number of pixels classified as ventilated and/or perfused

3. Matched Region \%: corresponding to the pixels which are both ventilated and perfused divided by the total number of pixels ventilated and/or perfused

\section{Statistical Analysis}

Sample size was similar to previous physiologic studies[19, 20]. Statistical analysis was performed via SPSS 26.0 (SPSS Inc. Chicago, IL) and Prism 8 (GraphPad Software, San Diego, CA, USA). All continuous variables were subjected to Shapiro-Wilk test for normality. Data was presented as mean \pm SD if normality was met, or otherwise as median and interquartile range. To test the effect of the time points on the variables, Mauchly's test was performed for sphericity and repeated measures ANOVA was applied with post hoc Bonferroni's multiple comparison. When violation of sphericity occurred (i.e. Mauchly's test $p$ value < 0.05), Greenhouse-Geisser method was used for correction. Correlation between continuous variables was assessed by Pearson regression coefficient. All statistical tests were two-tailed, and $p<0.05$ was considered statistically significant.

\section{Results}

\section{Patient characteristics}

A total of 10 ARDS patients who underwent mechanical ventilation in the ICU of Zhongshan Hospital, Fudan University from February 2021 to July 2021 were enrolled (Table 1). The patients consisted of 9 male and 1 female, aged $66 \pm 15$ with average body mass index (BMI) being $24 \mathrm{~kg} / \mathrm{m}^{2}$. The average APACHE $\otimes$ score at ICU admission was $14 \pm 9$. Three patients (30\%) had moderate ARDSand 7 patients (70\%) had severe ARDS. All patients underwent continuous PP for over 12 hours, with the average duration being $15.45 \pm 2.5$ hours. 
Table 1

Main characteristics of the patients

\begin{tabular}{|c|c|c|c|c|c|c|c|}
\hline $\begin{array}{l}\text { Patient } \\
\text { NO. }\end{array}$ & $\begin{array}{l}\text { Sex } \\
(M / F)\end{array}$ & $\begin{array}{l}\text { BMI } \\
\left(\mathrm{kg} / \mathrm{m}^{2}\right)\end{array}$ & $\begin{array}{l}\text { APACHE } \\
\text { score } \\
\text { at ICU } \\
\text { admission }\end{array}$ & $\begin{array}{l}\mathrm{PaO}_{2} / \mathrm{FiO}_{2} \\
\text { at } \\
\text { baseline } \\
(\mathrm{mm} \mathrm{Hg})\end{array}$ & $\operatorname{PEEP}\left(\mathrm{cmH}_{2} \mathrm{O}\right)$ & $\begin{array}{l}\text { Duration } \\
\text { of prone } \\
\text { positioning } \\
\text { (h) }\end{array}$ & $\begin{array}{l}\text { ARDS Etiology } \\
\text { (pulmonary/extrapulmonary) }\end{array}$ \\
\hline 1 & M & 25 & 33 & 83 & 10 & 12 & Pulmonary ARDS \\
\hline 2 & $M$ & 26 & 11 & 123 & 8 & 17 & Pulmonary ARDS \\
\hline 3 & $\mathrm{~F}$ & 35 & 9 & 51 & 14 & 18.5 & Extrapulmonary ARDS \\
\hline 4 & M & 24 & 19 & 81 & 11 & 16 & Extrapulmonary ARDS \\
\hline 5 & $M$ & 23 & 15 & 97 & 8 & 18.5 & Pulmonary ARDS \\
\hline 6 & $M$ & 21 & 2 & 97 & 8 & 16 & Pulmonary ARDS \\
\hline 7 & M & 21 & 7 & 140 & 5 & 15.5 & Extrapulmonary ARDS \\
\hline 8 & M & 26 & 11 & 96 & 5 & 12 & Pulmonary ARDS \\
\hline 9 & M & 19 & 23 & 64 & 12 & 16.5 & Pulmonary ARDS \\
\hline 10 & $M$ & 23 & 8 & 122 & 12 & 12.5 & Extrapulmonary ARDS \\
\hline Summary & $9 \mathrm{M} / 1 \mathrm{~F}$ & $24 \pm 4$ & $14 \pm 9$ & $95.4 \pm 27$ & $9.3 \pm 3.02$ & $15.45 \pm 2.5$ & $\begin{array}{l}6 \text { Pulmonary ARDS / } \\
4 \text { Extrapulmonary ARDS }\end{array}$ \\
\hline $\begin{array}{l}M, \text { male; } F \\
\text { respiratory } \\
\text { expiratory }\end{array}$ & $\begin{array}{l}\text { nale; BN } \\
\text { stress sy } \\
\text { ssure. }\end{array}$ & $\begin{array}{l}\text { Body } \mathrm{Ma} \\
\text { drome; } \mathrm{Pc}\end{array}$ & $\begin{array}{l}\text { Index; APA } \\
{ }_{2} / \mathrm{FiO}_{2} \text {, arte }\end{array}$ & $\begin{array}{l}\text { E-II Acute } \mathrm{F} \\
\text { I partial pre }\end{array}$ & $\begin{array}{l}\text { /siology and Ch } \\
\text { ure of } \mathrm{O}_{2} \text { /inspir }\end{array}$ & $\begin{array}{l}\text { nic Health } E \\
\text { I fraction of }\end{array}$ & $\begin{array}{l}\text { luation II; ARDS, acute } \\
\text { ratio; PEEP, positive end- }\end{array}$ \\
\hline
\end{tabular}

\section{Pp Improved Oxygenation And Hemodynamic Stability During Mechanical Ventilation}

Clinical parameters regarding respiratory and hemodynamic status at $T_{0}, T_{1}$ and $T_{2}$ were assessed and compared (Table 2). Notably, with PP administration, respiratory system compliance (Crs) ( 27.70 vs. 30.03 vs. $\left.33.52 \mathrm{ml} / \mathrm{cmH}_{2} \mathrm{O}, p<0.01\right)$, and $\mathrm{PaO}_{2} / \mathrm{FiO}_{2}$ (95.40 vs. 161.90 vs. $221.40 \mathrm{mmHg}, p<0.0001$ ) of the patients significantly increased. No significant difference was identified in minute ventilation (MV) $(p=0.536), \mathrm{PaCO}_{2}(p=0.257)$, end-tidal expired carbon dioxide pressure $\left(\mathrm{ETCO}_{2}\right)(p=0.348)$ or dead space percentage estimated by ABG (Dead space-ABG) $(p=0.740)$ among the 3 time points. 
Table 2

Effects of prone position ventilation on respiratory, gas exchange, and hemodynamics

\begin{tabular}{|c|c|c|c|c|c|}
\hline & $\mathrm{T}_{0}$ & $\mathrm{~T}_{1}$ & $\mathrm{~T}_{2}$ & $\begin{array}{l}\text { Trend-P } \\
\text { value }\end{array}$ & $\begin{array}{l}\text { Mauchly's test of sphericity } \\
P \text { value }\end{array}$ \\
\hline MV (I/min) & $7.47 \pm 1.09$ & $7.29 \pm 0.92$ & $7.62 \pm 1.32$ & 0.536 & $<0.001$ \\
\hline $\operatorname{Crs}\left(\mathrm{ml} / \mathrm{cmH}_{2} \mathrm{O}\right)$ & $27.70 \pm 11.65$ & $30.03 \pm 11.36$ & $33.52 \pm 12.87^{a}$ & $<0.01$ & 0.061 \\
\hline Set $\mathrm{FiO}_{2}$ & $\begin{array}{l}0.70[0.60- \\
0.89]\end{array}$ & $\begin{array}{l}0.60[0.59- \\
0.69]\end{array}$ & $\begin{array}{l}0.60[0.40- \\
0.65]\end{array}$ & $<0.05$ & 0.441 \\
\hline $\mathrm{PaO}_{2}(\mathrm{mmHg})$ & $66.98 \pm 12.15$ & $\begin{array}{l}100.44 \pm 20.54 \\
a\end{array}$ & $125.35 \pm 34.85$ & $<0.0001$ & 0.119 \\
\hline $\mathrm{PaO}_{2} / \mathrm{FiO}_{2}(\mathrm{mmHg})$ & $95.40 \pm 27.45$ & $\begin{array}{l}161.90 \pm 44.68 \\
\mathrm{a}\end{array}$ & $\begin{array}{l}221.40 \pm 54.64 \\
a, b\end{array}$ & $<0.0001$ & 0.957 \\
\hline $\mathrm{PaCO}_{2}(\mathrm{mmHg})$ & $\begin{array}{l}50.55[41.50- \\
63.35]\end{array}$ & $\begin{array}{l}56.45[46.33- \\
69.93]\end{array}$ & $\begin{array}{l}49.90[42.88- \\
68.58]\end{array}$ & 0.257 & 0.046 \\
\hline $\mathrm{ETCO}_{2}(\mathrm{mmHg})$ & $\begin{array}{l}36.00[34.00- \\
48.75]\end{array}$ & $\begin{array}{l}41.00[35.00- \\
50.00]\end{array}$ & $\begin{array}{l}37.50[33.00- \\
43.25]\end{array}$ & 0.348 & 0.010 \\
\hline Dead space-ABG & $\begin{array}{l}26.84[17.66- \\
34.42]\end{array}$ & $\begin{array}{l}24.56[21.64- \\
33.43]\end{array}$ & $\begin{array}{l}20.02[17.61- \\
37.17]\end{array}$ & 0.740 & 0.003 \\
\hline HR (bpm) & $113.30 \pm 19.81$ & $108.00 \pm 20.56$ & $106.90 \pm 24.53$ & 0.387 & 0.198 \\
\hline $\mathrm{SBP}(\mathrm{mmHg})$ & $116.20 \pm 17.50$ & $120.50 \pm 17.80$ & $121.60 \pm 19.00$ & 0.763 & 0.070 \\
\hline MAP $(\mathrm{mmHg})$ & $76.93 \pm 15.97$ & $84.83 \pm 13.77$ & $84.60 \pm 17.33$ & 0.360 & 0.092 \\
\hline CVP $(\mathrm{mmHg})$ & $\begin{array}{l}10.00[8.00- \\
14.50]\end{array}$ & $\begin{array}{l}14.00[10.50- \\
15.00]\end{array}$ & $\begin{array}{l}13.00[11.00- \\
15.00]\end{array}$ & 0.123 & 0.253 \\
\hline $\begin{array}{l}\text { Norepinephrine } \\
(\mu \mathrm{g} / \mathrm{kg} / \mathrm{min})\end{array}$ & $0.17[0-0.175]$ & $0.08[0-0.175]$ & $0.02[0-0.088]^{a}$ & $<0.05$ & 0.377 \\
\hline \multicolumn{6}{|c|}{$\begin{array}{l}\text { CVP, central venous pressure; } \mathrm{ETCO}_{2} \text {, end-tidal expired carbon dioxide pressure; } \mathrm{PaO}_{2} / \mathrm{FiO}_{2} \text {, arterial partial pressure of } \\
\mathrm{O}_{2} \text { /inspired fraction of } \mathrm{O}_{2} \text { ratio; } \mathrm{PaCO}_{2} \text {, arterial partial pressure of } \mathrm{CO}_{2} ; \mathrm{HR} \text {, heart rate; } \mathrm{MAP} \text {, mean arterial pressure; } \mathrm{SBP} \text {, } \\
\text { systolic arterial blood pressure. Respiratory system static compliance }(\mathrm{Crs})=\mathrm{Vt} /(\mathrm{Pplat}-\mathrm{PEEPtot}) \text { from the analysis of } \\
\text { ventilation tracings during occlusions. }\end{array}$} \\
\hline \multicolumn{6}{|c|}{$p$ value by one-way analysis of variance (ANOVA) for repeated measures } \\
\hline \multicolumn{6}{|l|}{ a vs. $T_{0}, p<0.05$} \\
\hline${ }^{b}$ vs. $T_{1}, p<0.05$ & & & & & \\
\hline
\end{tabular}

For hemodynamic parameters, decrease of heart rate (HR) and increase of systolic blood pressure (SBP), mean arterial pressure (MAP) and central venous pressure (CVP) were observed but with no significant difference reached. However, the dose of norepinephrine significantly decreased after the initiation of PP $(p<0.05)$, indicating the improvement of hemodynamic stability in the patients.

\section{Pp Altered Regional Distribution Of Lung Ventilation And Perfusion}

EIT-based measurements regarding lung ventilation and perfusion at the indicated time points were presented in Table 3 . Tidal image region-global\% significantly increased with PP administration ( $82.9 \%$ vs. $85.6 \%$ vs. $92.5 \%, p<0.0005)$, and the increments mainly took place in the dorsal region $(32.7 \%$ vs. $38.0 \%$ vs. $49.0 \%, p<0.005)$, while no significant decrease in the ventral region 
was observed (Fig. 1A). Similarly tendancy was also presented in the scale of the 4 ROls (Fig. 1B). Moreover, the GI index of ventilation progressively decreased from $\mathrm{T}_{0}$ to $\mathrm{T}_{2}(p<0.01$, Table 3$)$. 
Table 3

Physiologic variables at the three different time points selected for the analysis of electrical impedance tomography data

\begin{tabular}{|c|c|c|c|c|c|}
\hline Variables & $\mathrm{T}_{0}$ & $\mathrm{~T}_{1}$ & $\mathrm{~T}_{2}$ & $\begin{array}{l}\text { Trend-P } \\
\text { value }\end{array}$ & $\begin{array}{l}\text { Mauchly's test of } \\
\text { sphericity } P \text { value }\end{array}$ \\
\hline $\begin{array}{l}\text { Tidal image region-global } \\
(\%)\end{array}$ & $82.90 \pm 5.40$ & $84.60 \pm 7.31$ & $92.50 \pm 6.52^{a}$ & $<0.0005$ & 0.709 \\
\hline $\begin{array}{l}\text { Ventral of tidal image } \\
\text { region (\%) }\end{array}$ & $50.20 \pm 10.44$ & $46.60 \pm 8.61$ & $43.50 \pm 7.03$ & 0.140 & 0.030 \\
\hline $\begin{array}{l}\text { Dorsal of tidal image } \\
\text { region (\%) }\end{array}$ & $32.70 \pm 12.14$ & $38.00 \pm 9.24^{a}$ & 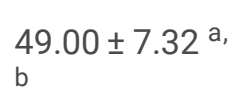 & $<0.005$ & 0.001 \\
\hline $\begin{array}{l}\text { ROI } 1 \text { of ventilation } \\
\text { distribution (\%) }\end{array}$ & $20.8 \pm 9.7$ & $15.8 \pm 7.0$ & $11.2 \pm 4.5$ & $<0.05$ & 0.099 \\
\hline $\begin{array}{l}\text { ROI } 2 \text { of ventilation } \\
\text { distribution (\%) }\end{array}$ & $\begin{array}{l}39.00[36.50- \\
43.00]\end{array}$ & $\begin{array}{l}37.00[35.25- \\
41.25]\end{array}$ & $\begin{array}{l}37.00[31.00- \\
42.00]\end{array}$ & 0.315 & 0.030 \\
\hline $\begin{array}{l}\text { ROI } 3 \text { of ventilation } \\
\text { distribution (\%) }\end{array}$ & $31.50 \pm 11.20$ & $36.30 \pm 7.85$ & $37.90 \pm 8.06$ & 0.243 & 0.013 \\
\hline $\begin{array}{l}\text { ROI } 4 \text { of ventilation } \\
\text { distribution (\%) }\end{array}$ & $7.50 \pm 3.24$ & $8.50 \pm 3.10$ & $15.00 \pm 3.744^{a}$ & $<0.001$ & 0.833 \\
\hline GI index-ventilation (\%) & $0.53 \pm 0.06$ & $0.52 \pm 0.07$ & $0.47 \pm 0.05^{a}$ & $<0.01$ & 0.266 \\
\hline $\begin{array}{l}\text { Blood flow region-global } \\
(\%)\end{array}$ & $73.9 \pm 9.9$ & $74.4 \pm 12.2$ & $75.3 \pm 7.2$ & 0.817 & 0.022 \\
\hline $\begin{array}{l}\text { Ventral of blood flow } \\
\text { region (\%) }\end{array}$ & $37.70 \pm 10.02$ & $36.30 \pm 8.52$ & $29.30 \pm 10.59$ & $<0.05$ & 0.102 \\
\hline $\begin{array}{l}\text { Dorsal of blood flow } \\
\text { region (\%) }\end{array}$ & $36.42 \pm 6.20$ & $38.20 \pm 7.98$ & $46.00 \pm 9.29^{a}$ & $<0.01$ & 0.623 \\
\hline $\begin{array}{l}\text { ROI } 1 \text { of perfusion } \\
\text { distribution }(\%)\end{array}$ & $12.10 \pm 4.66$ & $10.40 \pm 9.28$ & $9.60 \pm 10.89$ & 0.742 & 0.554 \\
\hline $\begin{array}{l}\text { ROI } 2 \text { of perfusion } \\
\text { distribution (\%) }\end{array}$ & $38.20 \pm 9.35$ & $37.90 \pm 5.59$ & $28.80 \pm 4.96^{a}$ & $<0.01$ & 0.268 \\
\hline $\begin{array}{l}\text { ROI } 3 \text { of perfusion } \\
\text { distribution (\%) }\end{array}$ & $40.20 \pm 7.00$ & $38.70 \pm 7.13$ & $42.30 \pm 7.15$ & 0.076 & 0.280 \\
\hline $\begin{array}{l}\text { ROI } 4 \text { of perfusion } \\
\text { distribution (\%) }\end{array}$ & $9.50 \pm 6.49$ & $13.00 \pm 8.65$ & $19.30 \pm 8.03$ & $<0.05$ & 0.148 \\
\hline GI index-perfusion (\%) & $0.60 \pm 0.12$ & $0.59 \pm 0.08$ & $0.59 \pm 0.10$ & 0.993 & 0.088 \\
\hline Matched region (\%) & $52.50 \pm 6.65$ & $61.10 \pm 7.39^{a}$ & $\begin{array}{l}67.40 \pm 7.09 \mathrm{a} \\
\mathrm{b}\end{array}$ & $<0.0005$ & 0.468 \\
\hline Dead space-EIT (\%) & $18.00 \pm 4.69$ & $18.10 \pm 5.02$ & $14.30 \pm 5.89$ & 0.099 & 0.154 \\
\hline Shunt-EIT (\%) & $29.50 \pm 7.56$ & $20.80 \pm 6.71^{a}$ & $18.30 \pm 6.06^{a}$ & $<0.005$ & 0.023 \\
\hline \multicolumn{6}{|c|}{$p$ value by one-way analysis of variance (ANOVA) for repeated measures } \\
\hline \multicolumn{6}{|l|}{ a vs. $T_{0}, p<0.05$} \\
\hline b vs. $T_{1}, p<0.05$ & & & & & \\
\hline
\end{tabular}


For lung perfusion, no obvious change was found in the global or ventral regional distribution of blood flow determined by EIT, but intriguingly, perfusion in the dorsal region was shown to be significantly increased with PP duration $(36.20 \%$ vs. $38.20 \%$ vs. $46.00 \%, p<0.05$ ) (Fig. 1C). Similarly, lung perfusion slightly decreased in the ventral ROI 1 and 2, while slightly increased in the dorsal ROI 3 and 4, though no statistical significance was reached (Fig. 1D). Besides, The GI index of perfusion remained constant during PP period (Table 3). These results indicated that the overall effect of PP on lung perfusion distribution was relatively mild, but still, PP could remarkably increase perfusion in the dorsal region of the lung.

\section{Pp Improved Ventilation-perfusion Matching}

Supplemental Fig. 2 showed ventilation and perfusion matching images of a patient at $T_{0}, T_{1}$ and $T_{2}$. Based on EIT measurements, Matched Region\% significantly increased with PP duration $(52.50 \%$ vs. $61.10 \%$ vs. $67.40 \%, p<0.0005)($ Fig. $2 \mathrm{~A})$. Intriguingly,Shunt-EIT \% significantly decreased with PP duration ( $29.50 \%$ vs. $20.80 \%$ vs. $18.30 \%, p<0.005$, Fig. $2 \mathrm{~B})$, especially between $\mathrm{T}_{0}$ and $\mathrm{T}_{1}$. Dead Space-EIT \% almost remained the same during PP administration (Fig. 2C). As shown in Fig. 2. D- F, $\mathrm{PaO}_{2} / \mathrm{FiO}_{2}$ presented high positive correlation with the percentage of Matched Region $\%($ rho $=0.601, p<0.0005)$ and high negative correlation with the level of shunt estimated by EIT (rho $=-0.484, p<0.01$ ), while no significant correlation with Dead Space-EIT \%. What' more, in our study, most of patients' lung had good recruitability after prone position sessions from CT scan (Figure S3).

\section{Discussion}

As a relatively new technique available for clinical use, EIT has provided an opportunity to dug into the physiological fundamentals of ARDS. In use of EIT, this study has provided some proof-of-concept evidences regarding the ventilationperfusion matching effect of PP during mechanical ventilation in ARDS patients. First, the increased ventilation was mainly distributed in the dorsal region while ventral ventilation was hardly changed, suggesting the aeration increment in dorsal lung regions was not offset by loss of aeration in ventral regions. Changes in ventilation were observed early in the prone position. Second, the redistribution effect of PP on lung perfusion was relatively mild compared to ventilation, with the dorsal lung perfusion increased and the trend of the ventral decreased, while global perfusion remained constant. Changes in blood flow were observed during prolonged prone positions. Third, ventilation-perfusion matched region was increased and correlated with the increased $\mathrm{PaO}_{2} / \mathrm{FiO}_{2}$ by $\mathrm{PP}$, which was specifically attributed to reduced functional shunt and increased dorsal ventilation and perfusion matching by the procedure.

During PP, patients exhibited a shift of the tidal volume distribution from the ventral to dorsal ROls, and the inhomogeneity of tidal ventilation distribution (GI) was reduced. In ARDS, with the lung weight usually increases by $2-3$ times, the potentially open alveoli at the dorsal region tend to collapse in the supine position. In the prone position, these alveoli may open up as the superimposed pressure of the dorsal regions is released [21]. Previous study reported that the inflation of pulmonary units was far more homogeneous at pronation than supination, which was interpreted as the lung-distending force (i.e. the gravitational gradient of pleural pressure, trans-pulmonary pressure or lung stress) was more homogeneously distributed [21, 22]. The primary reason was considered to be improved shape matching between the chest wall and the lung [23]. The gravitational gradient of pleural pressure, regional end-expiratory and end-inspiratory lung volumes, regional ventilation were all more uniform at prone position than at supine position [24].

Theoretically, the gravitational distribution of pulmonary blood flow is only minimally altered by pronation [25, 26], which is consistent with our findings. The increased perfusion in dorsal region and roughly maintained perfusion in ventral region could be attributed to less lung/heart geometry, fewer airspace compression of vessels (with more end-expiratory volume), and reduction of hypoxic vasoconstriction in dorsal region [5]. Similarly, Perier et al. recently reported that improvement of lung aeration and unmodified dorsal of pulmonary perfusion after three hours of the prone positioning in COVID-19-associated ARDS [27]. Unlike these studies we repeated EIT assessment at PP initiation, 3 hours after PP initiation and the end of PP within the first PP session. Based on theses evidences, we hypothesized that during prone ventilation, pulmonary blood flow remains unmodified at the early stage and then gradually increases in dorsal regions over time. 
In the present study, we found that Matched Region\% improved before the end of the prone position with the significant decrease in Shunt-EIT\%. Dead Space-EIT\% showed no significant difference but did show a mild reduction. The matching between lung ventilation and perfusion is fundamental to effective gas exchange, and both shunt and dead space are the determinants of ventilation-perfusion matching. In the present study, ventilation-perfusion matched region was increased by PP, and increased $\mathrm{PaO} 2 / \mathrm{FiO} 2$ was significantly correlated with increased matched region and reduced shunt, which was in accordance with previous studies [24, 28].

By recruiting the lungs, prone position has the potential to increase ventilation-perfusion matching, decrease hypoxemia, reduce hypoxic vasoconstriction, and thereby improve right ventricular function, hemodynamics and pulmonary perfusion. It is interesting to note that placing patients in prone position had a large impact on dose of vasopressors (norepinephrine was decreased from 0.17 to $0.02 \mathrm{ug} / \mathrm{Kg} / \mathrm{min}$ at the end of PP).

Although this study has provided notable evidences regarding physiological effects of prone ventilation in ARDS patients, its limitation should be noticed. First, this study was carried out within a small number of patients in a single center, which reduces the statistical power. Second, EIT measures only a portion of the lung, projecting the 3 dimensional distribution of ventilation/perfusion to the 2 dimensional image, which is not enough for assessment of the entire spectrum of ventilationperfusion matching in the lung [29]. Third, the EIT assessment was only performed at the 3 indicated time points during PP instead of throughout the process, which failed to fully uncover the longitudinal effect of PP. The present study missed the changes in ventilation and perfusion after resupination as well. Forth, cardiac output of the patients were not measured. The potential effect of PPV on $\mathrm{CO}$ might influence the oxygenation and V-Q matching.

\section{Conclusions}

Bedside EIT evaluation proved the concept that prolonged prone ventilation increased dorsal ventilation and perfusion in the lung, which resulted in improved ventilation-perfusion matching and consequently, oxygenation.

\section{Abbreviations}

ARDS

Acute respiratory distress syndrome

EIT

Electrical impedance tomography

PEEP

Positive end expiratory pressure

$\mathrm{Vt}$

Tidal volume

RR

Respiratory rate

$\mathrm{FiO}_{2}$

Fraction of inspired oxygen

$\mathrm{V} / \mathrm{Q}$

Ventilation/perfusion

$\mathrm{GI}$

Global Inhomogeneity

ROI

Region of Interest

\section{Declarations}

\section{Ethics approval and consent to participate}

Page 10/13 
The ethics review board of Zhongshan Hospital of Fudan University approved the study protocol and written informed consent was obtained from all participants before enrollment.

\section{Consent for publication}

Not applicable.

\section{Availability of data and materials}

The datasets used and/or analyzed during the current study are available from the corresponding author on reasonable request.

\section{Competing interests}

The authors have no potential conflicts of interest to declare.

\section{Funding}

This work was supported by National Natural Science Foundation of China (Grant NO.81971807). Drägerwerk AG \& Co. KGaA provided the software analysis tool for regional lung ventilation and perfusion measured by electrical impedance tomography free of charge.

\section{Authors' contributions}

YW takes responsibility for (is the guarantor of) the content of the manuscript, including the data and analysis. YW and MZ had full access to all of the data in the study and take responsibility for the integrity of the data and the accuracy of the data analysis, including and especially any adverse effects. MD, JS, YZ, WW, JT, LZ, and XZ contributed substantially to the study design, data analysis and interpretation, and the writing of the manuscript. All authors read and approved the final manuscript.

\section{Acknowledgements}

The authors thank all the subjects for their participation in this study.

\section{References}

1. Douglas WW, Rehder K, Beynen FM, Sessler AD, Marsh HM: Improved oxygenation in patients with acute respiratory failure: the prone position. Am Rev Respir Dis 1977, 115(4):559-566.

2. Pelosi P, Tubiolo D, Mascheroni D, Vicardi P, Crotti S, Valenza F, Gattinoni L: Effects of the prone position on respiratory mechanics and gas exchange during acute lung injury. Am J Respir Crit Care Med 1998, 157(2):387-393.

3. Guerin C, Reignier J, Richard JC, Beuret P, Gacouin A, Boulain T, Mercier E, Badet M, Mercat A, Baudin O et al: Prone positioning in severe acute respiratory distress syndrome. N Engl J Med 2013, 368(23):2159-2168.

4. Cornejo RA, Diaz JC, Tobar EA, Bruhn AR, Ramos CA, Gonzalez RA, Repetto CA, Romero CM, Galvez LR, Llanos 0 et al: Effects of prone positioning on lung protection in patients with acute respiratory distress syndrome. Am J Respir Crit Care Med 2013, 188(4):440-448.

5. Richter T, Bellani G, Scott Harris R, Vidal Melo MF, Winkler T, Venegas JG, Musch G: Effect of prone position on regional shunt, aeration, and perfusion in experimental acute lung injury. Am J Respir Crit Care Med 2005, 172(4):480-487.

6. Richard JC, Bregeon F, Costes N, Bars DL, Tourvieille C, Lavenne F, Janier M, Bourdin G, Gimenez G, Guerin C: Effects of prone position and positive end-expiratory pressure on lung perfusion and ventilation. Crit Care Med 2008, 36(8):23732380.

7. Katira BH, Osada K, Engelberts D, Bastia L, Damiani LF, Li X, Chan H, Yoshida T, Amato MBP, Ferguson ND et al: Positive End-Expiratory Pressure, Pleural Pressure, and Regional Compliance during Pronation: An Experimental Study. Am J Respir Crit Care Med 2021, 203(10):1266-1274. 
8. Martinsson A, Houltz E, Wallinder A, Lindgren S, Thorén A: Lung recruitment in the prone position after cardiac surgery: a randomised controlled study. Br J Anaesth 2021, 126(5):1067-1074.

9. Frerichs I, Amato MB, van Kaam AH, Tingay DG, Zhao Z, Grychtol B, Bodenstein M, Gagnon H, Bohm SH, Teschner E et al: Chest electrical impedance tomography examination, data analysis, terminology, clinical use and recommendations: consensus statement of the TRanslational EIT developmeNt stuDy group. Thorax 2017, 72(1):83-93.

10. Smit HJ, Vonk Noordegraaf A, Marcus JT, Boonstra A, de Vries PM, Postmus PE: Determinants of pulmonary perfusion measured by electrical impedance tomography. Eur J Appl Physiol 2004, 92(1-2):45-49.

11. Borges JB, Suarez-Sipmann F, Bohm SH, Tusman G, Melo A, Maripuu E, Sandstrom M, Park M, Costa EL, Hedenstierna G et al: Regional lung perfusion estimated by electrical impedance tomography in a piglet model of lung collapse. J Appl Physiol (1985) 2012, 112(1):225-236.

12. Kotani T, Tanabe H, Yusa H, Saito S, Yamazaki K, Ozaki M: Electrical impedance tomography-guided prone positioning in a patient with acute cor pulmonale associated with severe acute respiratory distress syndrome. J Anesth 2016, 30(1):161165.

13. Brunin Y, Despres C, Pili-Floury S, Besch G: Lung Recruiting Effect of Prone Positioning in Spontaneously Breathing COVID19 Patients Assessed by Electrical Impedance Tomography. Am J Respir Crit Care Med 2021.

14. Bernard GR, Artigas A, Brigham KL, Carlet J, Falke K, Hudson L, Lamy M, Legall JR, Morris A, Spragg R: The AmericanEuropean Consensus Conference on ARDS. Definitions, mechanisms, relevant outcomes, and clinical trial coordination. Am J Respir Crit Care Med 1994, 149(3 Pt 1):818-824.

15. Mauri T, Spinelli E, Scotti E, Colussi G, Basile MC, Crotti S, Tubiolo D, Tagliabue P, Zanella A, Grasselli G et al: Potential for Lung Recruitment and Ventilation-Perfusion Mismatch in Patients With the Acute Respiratory Distress Syndrome From Coronavirus Disease 2019. Crit Care Med 2020, 48(8):1129-1134.

16. Spinelli E, Kircher M, Stender B, Ottaviani I, Basile MC, Marongiu I, Colussi G, Grasselli G, Pesenti A, Mauri T: Unmatched ventilation and perfusion measured by electrical impedance tomography predicts the outcome of ARDS. Crit Care 2021, 25(1):192.

17. Yoshida T, Piraino T, Lima CAS, Kavanagh BP, Amato MBP, Brochard L: Regional Ventilation Displayed by Electrical Impedance Tomography as an Incentive to Decrease Positive End-Expiratory Pressure. Am J Respir Crit Care Med 2019, 200(7):933-937.

18. Zhao Z, Moller K, Steinmann D, Frerichs I, Guttmann J: Evaluation of an electrical impedance tomography-based Global Inhomogeneity Index for pulmonary ventilation distribution. Intensive Care Med 2009, 35(11):1900-1906.

19. Mauri T, Bellani G, Confalonieri A, Tagliabue P, Turella M, Coppadoro A, Citerio G, Patroniti N, Pesenti A: Topographic distribution of tidal ventilation in acute respiratory distress syndrome: effects of positive end-expiratory pressure and pressure support. Crit Care Med 2013, 41(7):1664-1673.

20. Patroniti N, Bellani G, Cortinovis B, Foti G, Maggioni E, Manfio A, Pesenti A: Role of absolute lung volume to assess alveolar recruitment in acute respiratory distress syndrome patients. Crit Care Med 2010, 38(5):1300-1307.

21. Gattinoni L, Pesenti A, Carlesso E: Body position changes redistribute lung computed-tomographic density in patients with acute respiratory failure: impact and clinical fallout through the following 20 years. Intensive Care Med 2013, 39(11):19091915.

22. Guerin C, Baboi L, Richard JC: Mechanisms of the effects of prone positioning in acute respiratory distress syndrome. Intensive Care Med 2014, 40(11):1634-1642.

23. Gattinoni L, Taccone P, Carlesso E, Marini JJ: Prone position in acute respiratory distress syndrome. Rationale, indications, and limits. Am J Respir Crit Care Med 2013, 188(11):1286-1293.

24. Galiatsou E, Kostanti E, Svarna E, Kitsakos A, Koulouras V, Efremidis SC, Nakos G: Prone position augments recruitment and prevents alveolar overinflation in acute lung injury. Am J Respir Crit Care Med 2006, 174(2):187-197.

25. Wiener CM, Kirk W, Albert RK: Prone position reverses gravitational distribution of perfusion in dog lungs with oleic acidinduced injury. J Appl Physiol (1985) 1990, 68(4):1386-1392. 
26. Glenny RW, Lamm WJ, Albert RK, Robertson HT: Gravity is a minor determinant of pulmonary blood flow distribution. J Appl Physiol (1985) 1991, 71(2):620-629.

27. Perier F, Tuffet S, Maraffi T, Alcala G, Victor M, Haudebourg AF, De Prost N, Amato M, Carteaux G, Mekontso Dessap A: Effect of Positive End-Expiratory Pressure and Proning on Ventilation and Perfusion in COVID-19 Acute Respiratory Distress Syndrome. Am J Respir Crit Care Med 2020, 202(12):1713-1717.

28. Lamm WJ, Graham MM, Albert RK: Mechanism by which the prone position improves oxygenation in acute lung injury. Am J Respir Crit Care Med 1994, 150(1):184-193.

29. van der Burg PS, Miedema M, de Jongh FH, Frerichs I, van Kaam AH: Cross-sectional changes in lung volume measured by electrical impedance tomography are representative for the whole lung in ventilated preterm infants. Crit Care Med 2014, 42(6):1524-1530.

\section{Figures}

\section{Figure 1}

Evolution of Tidal image region (\%), Blood flow region (\%), ventilation or perfusion distribution (\%) in the horizontal regions of interest (ROIs) at $\mathrm{T}_{0}, \mathrm{~T}_{1}$ and $\mathrm{T}_{2} .{ }^{*}$ vs. $\mathrm{T}_{0}, \mathrm{P}<0.05$. \# vs. $\mathrm{T}_{1}, \mathrm{p}<0.05$.

\section{Figure 2}

A, B, C. Comparisons of Matched Region (\%), Shunt-EIT (\%), and Dead Space-EIT (\%) at $T_{0}, T_{1}$ and $T_{2}$ * ${ }^{*}<0.05$. D, E, F. $\mathrm{PaO}_{2} / \mathrm{FiO}_{2}$ was significantly correlated with Matched Region\% and Shunt-EIT\%, but not with Dead Space-EIT\%.

\section{Supplementary Files}

This is a list of supplementary files associated with this preprint. Click to download.

- supplementalfigurelegend.docx

- FS1.tif

- FS2.tif

- FS3.tif 